\title{
Improving Undergraduate Learning For Employability Through International Exposure
}

Tim V. Eaton, Miami University, USA

Andrew S. Kleshinski, Ernst \& Young Undergraduate Scholar, USA

\begin{abstract}
The purpose of this study is to identify how undergraduate business programs can incorporate international exposure to increase employability among its graduates. We first examine how international opportunities in corporations have impacted the skills needed by employees to excel in a globalized work environment. From this, we identify desirable employee characteristics. Next, we discuss the research methodology to determine how highly ranked undergraduate business programs are adapting to employer demands. A four-tiered research approach is used to: identify criteria for measurement; select top undergraduate business programs for assessment; research university websites for curriculum requirements; and confirm observations directly with institutions. The findings show how universities have adapted undergraduate learning experiences to incorporate global exposure to help ensure graduates possess the required skills for employability. Finally, we discuss what characteristics many undergraduate business programs may lack in terms of international exposure and offer suggestions on how they could improve. This study should be of interest to university faculty and administrators by providing practical implications to aid undergraduate business programs in adopting initiatives, courses, and opportunities to stress an international focus for students. Introducing global education to a business curriculum could improve graduate job placement and improve a business program's overall ranking to external constituencies.
\end{abstract}

Keywords: Globalization; Employability; International Exposure; Study Abroad

\section{INTRODUCTION}

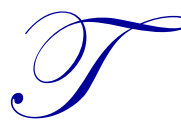

homas Friedman's famed book, The World is Flat, highlights an important phenomenon that has taken place in the $21^{\text {st }}$ century. Due to the evolution of technology, the world of business is morphing to a "level playing field" where domestic and international competitors have equal opportunities to capture customers and business globally. Ten historic "flatteners" are the key contributors to modern-day globalization, including events like the collapse of the Berlin Wall and innovations like offshoring and the internet. Adaptation to this changing market environment is essential for business survival in the increasingly competitive marketplace (Friedman, 2005).

Globalization has altered the business world indefinitely, as well as the skills needed by employees to excel in this new work environment. The global business mindset drastically increases the likelihood that a business has customers or suppliers abroad (Crossman \& Clarke, 2010). This rise in multinational corporations is directly linked with U.S. citizens being sent abroad on foreign work assignments. Clearly businesses are adapting to optimize performance in the era of globalization. However, this leads to several questions of interest to academia. Is the same adaptation exhibited by businesses also changing the way future employees are being educated? How are universities reacting to the changing work environment, specifically in regards to international exposure to increase the employability of their graduates? 
The purpose of this study is to identify how universities and undergraduate business programs incorporate international exposure to increase employability among its graduates in this new, global business climate. For the purpose of this study, employability should be understood as a candidate possessing the characteristics that an employer desires and which also allows them to be more successful in the workplace. This paper will examine how globalization created opportunities for businesses to operate internationally, and how this shift bolstered the market for expatriates. The following section analyzes the characteristics and experiences that employers seek in potential employees and how these have become more internationally focused. In order to best link changes in business climate with international university programming, we utilize a four-tiered research methodology to collect data. Using our research, we highlight how universities are currently implementing international learning into the curriculum. Along with describing university initiatives, we also elaborate on the benefits and potential for improvement with study abroad programs that allow students to continue their education in a foreign country for a period of time.

The study concludes by detailing what business programs lack and how they can most effectively cater the undergraduate experience to provide an internationally focused education. This could be accomplished through a variety of initiatives, including, but not limited to, study abroad experiences, diversity requirements, international studies courses, language development, and encouraging international student enrollment. Ultimately, the objective of these measures would be to enhance the employability of recent graduates and arm them with the desired international competencies that aide corporations in an era of globally "flat" business.

\section{International Focus and Opportunities in Corporations}

The business world is becoming increasingly global. In 2009, there were 889,416 multinational corporations (MNCs) worldwide, a number which has likely increased in the last three years (UNCTAD, 2009). Multinational corporations are companies whose operating facilities are located in more than one country. They may have one specific "central" or "home" location, but have various business interactions internationally. To stress the importance of MNC's, consider that in 2011, the 100 largest MNC's alone had revenues of over $\$ 8.7$ trillion. If these 100 multinational corporations were an economy, they would be the second largest in the world ahead of China (\$7.3 trillion) and over half as much as the United States (\$15.1 trillion) (UNCTAD, 2012).

These parent and affiliate companies need employees with adequate international exposure. Employees with intercultural understanding and previous international experience have a greater likelihood of success in the work environment. These experienced individuals have gained valuable skills to combat the difficulties of business interactions with foreign countries, companies, and business partners (Konopaske \& Werner, 2005).

Not only do businesses work with international customers and suppliers, but many require the use of expatriates to support their business abroad (Crossman \& Clarke, 2010). Expatriates are employees sent to a foreign country for a period of time to work abroad prior to returning back to their home country. Expatriates have a number of considerations prior to taking an overseas position which include compensation, taxation, and family displacement (Suutari \& Tornikoski, 2001). Other critical factors that are linked with expatriate success include business culture and individual ability to adapt. These two factors can be directly impacted by the previous international exposure of the expatriate. For recent graduates, these opportunities present themselves during their tenure as students.

\section{Desirable Employee Characteristics}

The abundance of international business opportunities creates the necessity for employers to alter their list of desired characteristics and competencies for potential employees. Historically, there have been many key skills required for success as an employee in the business world, often relating to the way employees think and approach problems. These skills, such as intellectual capacity, problem solving ability, communication skills, and leadership, are widely accepted as critical attributes. This study will not examine these skills because they are, and will always be, sought out by employers. Instead, we will focus our attention on skills and characteristics that are internationally focused and may have become more desirable as a result of globalization. We have reviewed the current literature to arrive at a preliminary list of global competencies, though we recognize it is not all-encompassing. These are often 
considered differentiating characteristics, meaning they distinguish between an average and above-average employee. Also, many of the following skills are more applicable to businesses competing on an international level as compared with those operating strictly within local or national borders.

The first distinguishing competency will be referred to as the ability to operate globally. This is a broad trait which describes an employee that has international experience, is adaptable, and is willing to subject themselves to various situations, places, and cultures. This trait relates well to employees with previous international experience because it shows their willingness to expand their horizons and adapt to foreign cultures. Traveling outside of someone's comfort zone requires an open mindset and comfort with the uncomfortable, which for many, is no simple task. Having the ability to operate globally is now more important than ever because business interactions could be with anyone across the globe due to globalization (Jackson, 2010). Despite some language skills being needed for the literal ability to communicate (operate) globally, this trait is so important that we explicitly examine its merits as a desirable competency later in this section.

The next competency area is intercultural understanding. Ability to make culturally-sensitive decisions coupled with knowledge about foreign cultures and norms appropriately describes intercultural understanding. This skill has more specified knowledge than simply the ability to operate globally. Instead of simply interacting with others while abroad, intercultural understanding helps ensure success while conducting business internationally. This is critical for a business trying to manage interactions with diverse business suppliers, customers, clients, and coworkers. Diverse, in this context, refers to people with varying cultures, races, geographical location, and viewpoints. This is particularly critical because appropriate business conduct can vary drastically between groups of people. Awareness of other cultures norms can help avoid misunderstandings, frustration, and even offending others (Crossman \& Clarke, 2010). For instance, certain business practices may be deemed severely inappropriate in a foreign culture. Understanding and adhering to these norms is of the utmost importance to maintain favorable relations with international customers, suppliers, or investors (Stagno, 2012).

Fluency in foreign languages is critically important as a distinguishing characteristic for potential employees. These skills are not yet deemed a necessity for employment, likely due to the adoption by many of English as an international language of business (Jackson, 2010). However, despite not yet being required, employers are recognizing the importance a second language has, and will have, to the future of business. The U.S. Department of Defense has implemented the National Security Education Program (NSEP) to determine skills needed for businesses in the global economy. Many of their findings uncover costly difficulties with translating for international clients, loss of productivity due to language barriers, and failing to provide appropriate resources for non-English speaking employees. Other than English, Chinese, Spanish, Arabic, French, Hindi, Russian, and Portuguese are recognized as the most important languages for communication in the global markets. The importance of Portuguese is directly linked with Brazil being an emerging market, French for widespread communication throughout Africa, and Chinese because many experts predict it will be the predominant language across Asia within the next 10 years (Duggan, 2009). To stay competitive and avoid costly language difficulties, companies operating internationally clearly have the need and desire for employees with foreign language skills.

\section{RESEARCH METHODOLOGY}

We have analyzed the literature to express how globalization has impacted the business world and the abundance of international opportunities available to the workforce. Additionally, several other studies have detailed changes in desirable employee characteristics as business needs have progressed. We focus on the link between these changes in business needs and how undergraduate business programs have responded to improve the employability of students. The research questions for our study are as follows:

- Have undergraduate business programs recognized the importance of foreign language as a skill for success in the workplace? How many schools have these requirements? Is there any specific language that is required, or is it up to the students to decide?

- To what extent have universities adopted a curriculum which includes courses dedicated to global learning? Will these teach intercultural understanding? 
- $\quad$ Do these universities have any study abroad programs offered to their students? What percentage of schools provide this option? And do any actually require students to go abroad? Does this promote the ability of their students to operate globally and how many students choose to pursue these options assuming they aren't required?

In order to examine how universities are adapting to an international business climate, we coupled the prior analysis with a four-tiered research approach to retrieve data from top undergraduate business programs.

First, we identified measurement criteria. We listed commonly recognized requirements and opportunities for students to gain international exposure from an undergraduate business program. The first criteria for measurement would be which universities had foreign language requirements for their business students. When applicable and measureable, the number of credit hours or proficiency level required was also recorded. The study would also include if these programs had any internationally focused class requirements. Examples of classes with an international focus include international culture, international business, cultural competence, strategic global management, and global issues. The last criteria was whether study abroad programs were offered or required, and as well as the frequency of participation for students without requirements.

Second, we selected the universities for our study. A list of the top 50 undergraduate business programs was compiled according to the 2012 U.S. News and World Report. These universities achieved their rank based on peer assessment surveys completed by Business School Deans and other faculty members. Ipsos Public Affairs conducted the study throughout the spring of 2012. The surveys rated business program quality on various subfactors used to calculate seven main criteria used for the rankings. The main criteria are; undergraduate academic reputation; student selectivity for entering class; faculty resources for academic year; graduation and retention rates; financial resources; alumni giving; and graduation rate performance. Sub-factors such as the university's acceptance rate, composite ACT score, and scores from portions of the SAT are all also used to determine the main criteria, "student selectivity for entering class." In order to be eligible for the survey, each university must be accredited by the Association to Advance Collegiate Schools of Business. ${ }^{1}$

Third, once the measurement methods and select study group were determined, we searched university websites for information regarding the selected criteria. For each business program on the list, we searched for graduation requirements and compared them with our predetermined criteria. We recorded any relevant information and compiled our data on a master spreadsheet. This initial search was limited to easily accessible information from each university and the extent to which they explain their business program or study abroad offerings.

\footnotetext{
${ }^{1}$ http://www.usnews.com/education/best-colleges/articles/2012/09/11/methodology-undergraduate-ranking-criteria-and-weights-2 


\begin{tabular}{|l|l|l|l|}
\hline 1 & Arizona State University & 26 & The Ohio State University, Columbus \\
\hline 2 & Auburn University & 27 & The University of Arizona \\
\hline 3 & Babson College & 28 & The University of Iowa \\
\hline 4 & Bentley University & 29 & The University of North Carolina \\
\hline 5 & Boston College & 30 & The University of Texas at Austin \\
\hline 6 & Boston University & 31 & Tulane University \\
\hline 7 & Brigham Young University & 32 & University of Arkansas \\
\hline 8 & Carnegie Mellon University & 33 & University of California, Berkeley \\
\hline 9 & Case Western Reserve University & 34 & University of Colorado, Boulder \\
\hline 10 & College of William and Mary & 35 & University of Florida \\
\hline 11 & Cornell University & 36 & University of Georgia \\
\hline 12 & Emory University & 37 & University of Illinois, Urbana-Champaign \\
\hline 13 & Georgetown University & 38 & University of Maryland, College Park \\
\hline 14 & Georgia Institute of Technology & 39 & University of Michigan, Ann Arbor \\
\hline 15 & Indiana University,Bloomington & 40 & University of Minnesota, Twin Cities \\
\hline 16 & Massachusetts Institute of Technology & 41 & University of Notre Dame \\
\hline 17 & Michigan State University & 42 & University of Pennsylvania \\
\hline 18 & New York University & 43 & University of Pittsburgh \\
\hline 19 & Penn State University Park & 44 & University of South Carolina at Columbia \\
\hline 20 & Purdue University,West Lafayette & 45 & University of Southern California \\
\hline 21 & Rensselaer Polytechnic Institute & 46 & University of Virginia \\
\hline 22 & Southern Methodist University & 47 & University of Washington \\
\hline 23 & Syracuse University & 48 & University of Wisconsin, Madison \\
\hline 24 & Texas A\&M University & 49 & Wake Forest University \\
\hline 25 & The George Washington University & 50 & Washington University in St Louis \\
\hline
\end{tabular}

Figure 1: List of Top Ranked Undergraduate Business Programs in Alphabetical Order

Lastly, these findings were supported by direct contact with the members of the advising staff from each university. The following three questions were sent by email to strengthen the findings from our initial web searches:

1) Is there any foreign language requirement for business students (please mark yes even if it is through the university core curriculum)? If so, how many credit hours are required?

2) Are there any required international or global courses for business students (excluding a foreign language)? If so, how many credit hours are required? Could you please list these courses?

3) Is a study abroad program required for business students? If it is not required, what percentage of business students participate in a study abroad program?

Once we received a reply, the information was recorded in the excel spreadsheet and used to verify or amend data from the previous collection. Once all the information was collected, we were able to draw conclusions and identify patterns among top undergraduate business programs based on the results. We sent out 50 email questionnaires, one to an advising faculty from every undergraduate business program chosen for the study. From the initial round of questionnaires, $36 \%$ of advisors responded directly with answers, while another $4 \%$ forwarded the email to another faculty member that responded. A second wave of identical questionnaires was sent to a different advisor from the remaining universities which had not yet replied. The second set received an additional $32 \%$ of the total universities. Thus, out of the top 50 undergraduate business programs, our email questionnaire response rate was $72 \%(40 \%+32 \%)$. This high response rate demonstrates university interest in the objectives of this study.

\section{Research Results and University Efforts for International Exposure}

Our findings show that among the top 50 undergraduate business programs, 25 , or $50 \%$ require some foreign language proficiency. Most universities with foreign language requirements offer proficiency examinations for students to place into an advanced language course, or test out of the requirement completely. The level required for students varied too greatly to reach a consensus proficiency level depending on whether the universities used 
semesters, trimesters, or quarters for the academic year. This evidence seems to contradict the declining necessity of foreign language skills for the global workplace, even though English is more widely used in cross-cultural business interactions. However, this supports the notion that universities want to distinguish their students to employers by providing skillsets beyond what is required for employment eligibility.

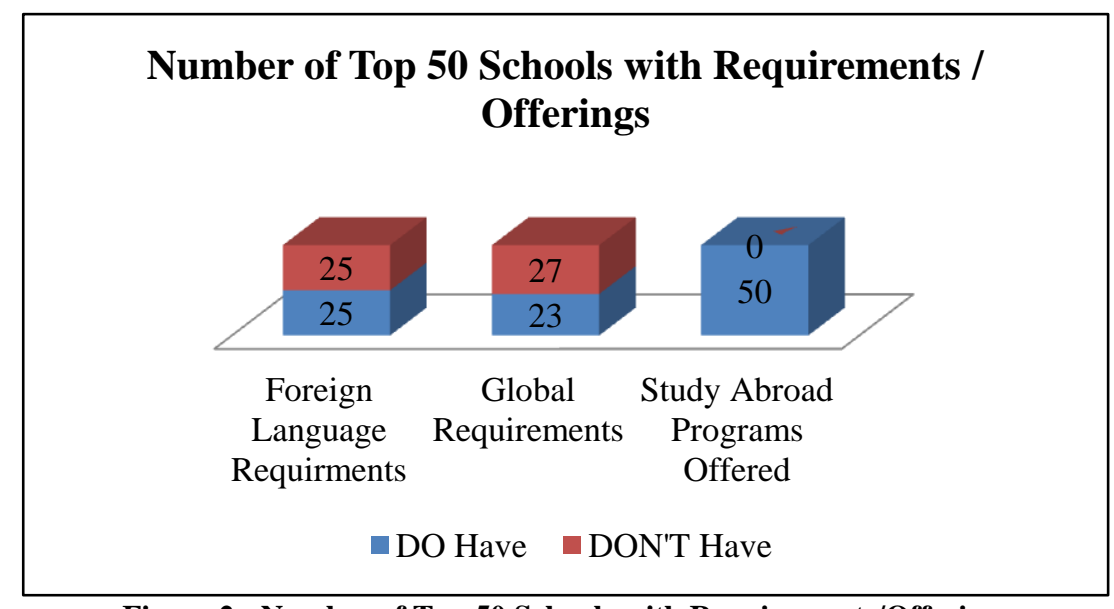

Figure 2: Number of Top 50 Schools with Requirements/Offerings

These findings support our initial hypothesis that curriculum has developed to incorporate more global understanding courses. We found that $46 \%$ require internationally focused classes. These requirements show universities striving to instill graduates with the ability to operate globally and cultural diversity management competencies as previously mentioned in the desirable employee characteristics section. These students can gain knowledge and appreciation for foreign cultures and business practices to help them in the global workforce.

We found that $100 \%$ of our surveyed programs offer a variety of study abroad programs for students to choose from. These include strategic partnerships with other universities to provide an international experience for students, experiences available only to students of a particular university, and even branch campuses located internationally. Some universities have even gone so far as to make study abroad programs mandatory for business students to graduate and fulfill their curriculum requirements. In the study, only 1 of the 50 school, or $2 \%$ of business programs require students to study abroad.

Some of the email responses to our questionnaires included an approximate estimate of the $\%$ of students who choose to study abroad. Of these specific responses received, 28 of the top 50 schools, or $56 \%$, provided an average estimate of $36.2 \%$ of students deciding to study abroad that were not required to do so. When advisers replied with a range of estimates of participants (i.e., 30-40\% study abroad), a simple midpoint (i.e., 35\%) was used in the calculation of the average percentage of students that study abroad.

\section{HOW TO IMPROVE GLOBAL EDUCATION}

This study has examined global market trends, new qualities which employers desire in employees, and a primary research initiative to determine how universities have adapted to the global business environment. The next section will combine our research efforts with the literature to determine broad ways in which institutions of higher learning, specifically undergraduate business programs, can improve their curriculum. Undergraduate business students require more foreign language proficiency than the average American, though evidence suggests there should be an even larger emphasis. Additionally, due to the benefits of study abroad experiences and their cost prohibitive nature, we expect future scholarship opportunities to arise, allowing more student participation. Other studies show the benefits of global learning for business professors, an area that future research may also examine.

With regards to foreign language development, the United States is considered lacking relative to many other countries competing in the global economy. A small percentage of the population, (less than 20\% in 2010) is 
considered bilingual, though this percent has increased considerably over the past several decades. In 1980 approximately $11 \%$ of Americans knew a second language, which increased to 14\% by 1990 (Grosjean, 2010). The afore-mentioned studies by the National Security Education Program, urge higher education institutions to continue this trend. This is especially important given the likelihood Chinese, Spanish, Arabic, French, Hindi, Russian, and Portuguese will be more prevalent in the global market (Duggan, 2009). Our research showing 50\% of the top 50 undergraduate business programs requiring foreign language for graduation may show some support for this initiative. However, an argument could be made that business students, especially from top universities, should have an even higher participation in foreign language. Additionally, the institutional requirements don't necessarily guarantee students are fluent or considered bilingual in a second language, which are especially difficult to compare given the variety of requirements for 'proficiency.' As such, global education can be improved considerably by having a heavier emphasis and requirement for foreign language development.

Students can clearly benefit from participation in study abroad programs. As such, we see two primary changes which undergraduate business programs should implement to improve global education and employability of their graduates. First, study abroad programs need to be tailored so that the emphasis isn't on the abroad experience, but rather the learning outcomes from that experience and how it is applicable in the workplace. Programs need to distance themselves from historic perceptions of simply being a "perk for wealthy students at selective colleges," towards a value-added experience that can benefit future employers (Fischer, 2010). Universities can optimize learning by adequately preparing the students for the experience. For example, students should be informed about cultural differences and encouraged to study foreign literature. This prior acclimation to the foreign culture will help expedite comfort and minimize shock for the students. Additionally, there should be a greater emphasis on post-processing after the student returns to their home country. Thoughtful reflection and review of the experience can help solidify learning (Kruse \& Brubaker, 2007). Additionally, programs should be applicable to the global work environment. For example, University of Michigan already focuses on teaching students how to use the knowledge gained overseas in specific employment fields and helps students find international internships. These measures help students excel and gain the most from a study abroad experience. With this support, students achieve learning outcomes like the ability to operate globally and work in a cross-cultural environment - something an employer desires that would certainly improve student education (Fischer, 2010).

Secondly, given the benefit from study abroad programs, universities should find ways to increase participation. Our research shows that $100 \%$ of the top 50 undergraduate business programs offer study abroad experiences to their students. From those universities with reliable estimates on study abroad participation rates among students not required to study abroad, the average participation was $36.2 \%$. Additionally, only $2 \%$ of programs require study abroad. There is clearly a large discrepancy between the students that could and choose to study abroad. We believe that this limited number is primarily due to the financial burden often associated with studying abroad. Expensive international flights and various program fees may make these programs cost prohibitive for students, especially those requiring financial assistance to finance their higher education. As such, we predict that in the future, students may see an increase in scholarships offered for pursuing international opportunities. Making these valuable global learning experiences affordable will aid global learning and increase participation rates in study abroad experiences. Universities can build relationships with corporations and other private donors to help provide scholarships and endowments to better support these international experiences.

An interesting research study was published in the Journal of Education for Business regarding the experience that university faculty have during short-term study abroad programs. The article recognized that not only may students have impactful experiences, but that business professors may as well. Graduate students and professors from Middle Tennessee State University studied for two-weeks in Japan. Research indicated that professors receive a variety of learning outcomes from the travel, namely intellectual growth and acculturation. For this study, intellectual growth is simply understood as obtaining knowledge through the international experience. Another learning outcome, acculturation, refers to dispelling misperceptions of another culture that may be unintentionally transferred to students from professors. These experiences may fix biases and improve teaching, especially classes emphasizing international content. This is important because it shows global learning, specifically through study abroad programs, is applicable to faculty members and students alike. Not only can these programs develop these professors, but future students will also benefit from their improved knowledge and global perspectives which will be used in future lessons (Festervand \& Tillery, 2001). Given these findings business 
programs should not only focus on the education of students, but also professors in order to optimize global learning.

The global business market has been undeniably changed. Due to the fundamental shift in scope of businesses from a local to the global level, the skills required for employees to be successful have changed as well. As such, universities must adapt to these changing business needs to prepare their students for employability, which is a primary reason for higher education. This study helps identify trends within the top business programs across the United States to see what progress has already been made, and some areas that need improvement for students and faculty alike.

\section{ACKNOWLEDGEMENT}

The authors gratefully acknowledge generous research funding from Ernst \& Young, LLP.

\section{AUTHOR INFORMATION}

Dr. Tim V. Eaton is Associate Professor and Ernst \& Young Teaching Scholar at Miami University in Oxford Ohio. He has published over 40 articles covering a wide range of accounting topics. E-mail: eatont@muohio.edu (Corresponding author)

Andrew S. Kleshinski is an Undergraduate Student and Ernst \& Young Undergraduate Scholar at Miami University in Oxford, Ohio.

\section{REFERENCES}

1. Crossman, J., \& Clarke, M. (2010). International experience and graduate employability: Stakeholder perceptions on the connection. Higher education. The International Journal of Higher Education and Educational Planning, 59(5), 599-613.

2. Duggan, S. (2009). What business wants: Language needs in the $21^{\text {st }}$ century. The Language Flagship, National Security Education Program.

3. Festervand, T., \& Tillery, K. (2001). Short-term study-abroad programs-a professional development tool for international business faculty. Journal of Education for Business, 77(2), 106-111.

4. Fischer, K. (2010). Study abroad's new focus is job skills. Chronicle of Higher Education, 57(9), 1-21.

5. Friedman, T. L. (2005). The world is flat: A brief history of the twenty-first century. New York, NY: Farrar, Straus and Giroux.

6. $\quad$ Grosjean, F. (2010). Bilingual: Life and reality. Cambridge, MA: Harvard University Press.

7. Holoviak, J., Verney, T., Winter, A., \& Holoviak, S. (2011). Assessing academic performance through study abroad: Benefits of the experience. Research in Higher Education Journal, 11(1), 1-10.

8. Jackson, D. (2010). An international profile of industry-relevant competencies and skill gaps in modern graduates. International Journal of Management Education, 8(3), 29-58.

9. Konopaske, R., \& Werner, S. (2005). US managers' willingness to accept a global assignment: Do expatriate benefits and assignment length make a difference? International Journal of Human Resource Management, 16(7), 1159-1175.

10. Kruse, J., \& Brubaker, C. (2007). Successful study abroad: Tips for student preparation, immersion, and postprocessing. Die Unterrichtspraxis/Teaching German, 40(2).

11. Loh, C. A., Steagall, J. W., Gallo, A., \& Michelman, J. E. (2011). Valuing short-term study abroad in business. Journal of Teaching in International Business, 22(2), 73-90.

12. Orahood, T., Woolf, J., \& Kruze, L. (2008). Study abroad and career paths of business students. Frontiers: The Interdisciplinary Journal of Study Abroad, 17(1), 133-141.

13. Parker, P. (2008). Promoting employability in a 'flat' world. Journal of Employment Counseling, 45(1), 213.

14. Smith, D. E., \& Mitry, D. J. (2008). Benefits of study abroad and creating opportunities: The case for shortterm programs. Journal of Research in Innovative Teaching, 1(1), 236-246. 
15. Stagno, G. (2012 June 4). Business in Japan. Miami University Pacific Rim Seminar. Japan, Tokyo. Lecture.

16. Suutari, V., \& Tornikoski, C. (2001). The challenge of expatriate compensation: The sources of satisfaction and dissatisfaction among expatriates. The International Journal of Human Resource Management, 12(3), 389-404.

17. United Nations Conference on Trade and Development (UNCTAD), (2009). World investment report 2009: Transnational corporations, agricultural production and development. Geneva: United Nations.

18. United Nations Conference on Trade and Development (UNCTAD), (2012). World investment report 2012: Towards a new generation of investment policies. Geneva: United Nations.

19. US News \& World Report L.P. (2012). The best undergraduate business programs. New York, NY. 
NOTES 